\title{
Synthesis and Enzymatic Degradation of Environmentally Benign Poly(carbonate-urethane)
}

\author{
Saeko Murakami, ${ }^{*}$ Nobuyoshi Aoki, ${ }^{1}$ Shuichi Matsumura ${ }^{2}$ \\ ${ }^{* 1}$ Kanagawa Industrial Technology Center, 705-1, Shimoimaizumi, Ebina 243-0435, Japan \\ Fax: 81-46-236-1525, e-mail: murakami@kanagawa-iri.go.jp \\ ${ }^{2}$ Faculty of Science and Technology, Keio University, 3-14-1 Hiyoshi, Kohoku-ku, Yokohama 223-8522, Japan \\ Fax: 81-45-566-1582, e-mail: matumura@applc.keio.ac.jp
}

Enzymatically cleavable poly(carbonate-urethane) was prepared by the polymerization of hexamethylene diisocyanate with oligo(tetramethylene carbonate) diol as a soft segment. The oligo(tetramethylene carbonate) diol was prepared by the lipase-catalyzed oligomerization of 1,4-butanediol and diethyl carbonate. The tensile strength and elongation of the poly(tetramethylene carbonate-urethane) film exhibited properties similar to those of the polyethylene (LDPE) film. Poly(tetramethylene carbonate-urethane) was degraded at the carbonate linkages by lipase to produce cyclic oligomers.

Key words: degradation, environmentally benign polyurethanes, enzymes, lipase, poly(carbonate-urethane)

\section{INTRODUCTION}

The greening of chemistry in the field of polymer science may include the design and synthesis of biodegradable and chemically recyclable plastics, and the application of environmentally benign catalysts, such as enzymes. The advantages of using a hydrolysis enzyme for polymer production may be the reversible reaction between polymerization and degradation that enables the chemical recycling and the metal-free polymerization. Polymer chains containing hydrolyzable linkages, such as ester and carbonate linkages, can be cleaved by the action of the hydrolysis enzyme. It is reported that poly(carbonate-urethane) is enzymatically degradable.[1,2] Thus, the enzymatically cleavable polyurethane will be produced by combining the biodegradable oligo(alkylene carbonate) diols with urethane linkages. Although the water resistance and stability of poly(carbonate-urethane) are generally higher than those of poly(ester-urethane)s, the produced poly(carbonate-urethane) will be cleaved into oligomers by the action of lipase. The oligomer can be repolymerized by lipase for chemical recycling. Furthermore, the poly(carbonate-urethane) can be biodegraded by environmental microbes, first cleaving the polymer chain using a microbial hydrolysis enzyme.

Polyurethane is widely used in various fields, such as the manufacture of plastic foams, cushions, rubber goods, synthetic leathers, adhesives, paints, and fibers. Conventional simple and high-molecular weight polyurethanes without hydrolyzable linkages are generally resistant to biodegradation. [3] This may be ascribed to both the complexity of the molecular structures and lack of enzymatically cleavable linkages in the polymer chain. However, it is known that the urethane oligomer can be hydrolyzed by some microorganisms and that the hydrolysis is catalyzed by an esterase. $[4,5]$ The biodegradation of polyurethane containing some hydrolyzable groups has been reported. Darby et al. first reported that the polyester-type polyurethane is more susceptible to microbial attack than the polyether-type polyurethane.[6] The microbial degradation of poly(ester-urethane) is thought to be mainly due to the hydrolysis of ester bonds by esterases or lipases.[7-9] The polyester segment of the polyurethane is the first cleaving site of the polymer. The oligomeric urethane will then be further degraded. $[10,11]$ One of the authors previously reported that molecularly pure and biodegradable diurethane moiety as a hard segment was combined by an enzymatically hydrolyzable carbonate or ester linkages to produce a novel biodegradable poly(carbonate/ester-urethane). The polyurethanes were readily transformed into a repolymerizable cyclic oligomer by lipase in an organic solvent. Thus, the produced poly(carbonate-urethane) and poly(ester-urethane) are chemically recyclable by lipase in addition to being biodegradable. [12, 13]

In this report, a novel enzymatically cleavable poly(carbonate-urethane) was prepared by combining the biodegradable oligo(alkylene carbonate) diols with urethane linkages using hexamethylene diisocyanate without a catalyst as shown in Scheme 1 .

$$
\begin{aligned}
& \left.\mathrm{C}_{2} \mathrm{H}_{5} \mathrm{O}-\mathrm{O}-\mathrm{C}-\mathrm{OC}_{2} \mathrm{H}_{5} \frac{\mathrm{HO}_{\mathrm{O}} \mathrm{CH}_{2} \mathrm{O}_{x} \mathrm{OH}}{\text { Lipase CA }} \mathrm{HO}+\mathrm{CH}_{2}\right)_{x} \circ\left[\mathrm{O}\left[\mathrm{O}-\mathrm{O}-\mathrm{CH}_{2}\right)_{x} \circ\right]_{\pi} \mathrm{H}
\end{aligned}
$$

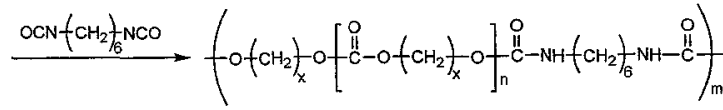

$$
\begin{aligned}
& \text { Scheme } 1 \\
& \mathrm{x}=4: \text { PTeCU, } 6: \text { PHCU }
\end{aligned}
$$

\section{EXPERIMENTAL PART}

2.1 Materials and Measurements

Diethyl carbonate was purchased from WAKO Pure Chemical Industries, Ltd. (Osaka, Japan). Candida antarctica lipase immobilized on acrylic resin [CA: Novozym 435 (triacylglycerol hydrolase + carboxylesterase) having 10,000 PLU/g (propyl laurate units: lipase activity based on ester synthesis)] was 
supplied by Novozymes Japan Ltd. (Chiba, Japan). The enzyme was used without further purification. The enzymes was dried in vacuum over $\mathrm{P}_{2} \mathrm{O}_{5}$ at $25^{\circ} \mathrm{C}$ for $6 \mathrm{~h}$. Oligo(hexamethylene carbonate) diols [oligo(HC) diol: $M_{\mathrm{n}}=1,500$ and 3,900, respectively, as measured by SEC using polystyrene standards] were purchased from Aldlich Chem. Co., Inc. (Milwaukee, WI, USA). The other materials used were of the highest available purity.

The weight-average molecular weight $\left(M_{\mathrm{w}}\right)$ and the number-average molecular weight $\left(M_{n}\right)$ for the polymers were measured by a size exclusion chromatography (SEC) using SEC columns (TSKgel G4000HXL + TSKgel G2500HXL + TSKgel G1000HXL, TOSOH Ltd., Tokyo, Japan) at $40{ }^{\circ} \mathrm{C}$ with a refractive index detector. Tetrahydrofran was used as the eluent at 1.0 $\mathrm{mL} / \mathrm{min}$. The SEC system was calibrated with polystyrene standards of narrow molecular weight distribution. The molecular weight was also measured by the matrix-assisted laser desorption ionization time-of-flight mass spectrometry (MALDI-TOF MS) with a Bruker Ultraflex mass spectrometer. The spectrometer was equipped with a nitrogen laser. The detection was in the reflectron mode. 2,5-Dihydroxybenzoic acid was used as the matrix and positive ionization was used. Sodium bromide was used as the cation source. The ${ }^{1} \mathrm{H}$ NMR spectra were recorded with a FT-NMR Spectrometer JNM-A 400 (JEOL, Ltd., Tokyo, Japan) operating at $400 \mathrm{MHz}$. IR spectra were recorded with a FT-IR 8200PC (Shimadzu Corp., Kyoto, Japan).

The glass-transition temperature $\left(T_{\mathrm{g}}\right)$ of the polymer was measured with a differential scanning calorimetry (DSC-3100, Mac Science Corp.). The heating rate was $10^{\circ} \mathrm{C} / \mathrm{min}$ within a temperature range of -50 to $180^{\circ} \mathrm{C}$. Each polymer sample weighed approximately $3-5 \mathrm{mg}$. The polymer samples were heated at a rate of $10^{\circ} \mathrm{C} / \mathrm{min}$ from $-50^{\circ} \mathrm{C}$ to $180^{\circ} \mathrm{C}$ (first heating), rapidly cooled at a rate of $-50{ }^{\circ} \mathrm{C} / \mathrm{min}$ to $-50{ }^{\circ} \mathrm{C}$ and then scanned at the same heating rate and over the same temperature range (second heating). The $T_{\mathrm{g}}$ and $T_{\mathrm{m}}$ values were collected from the second heating. Tensile strength and elongation of poly(carbonate-urethane) film were measured by Universal Testing Machine Tensilon RTC-1250 (Orientec Co.,Ltd., Tokyo, Japan).

2.2 General Enzymatic Oligomerization Procedure of Oligocarbonate Diol

Oligo(tetramethylene carbonate) diol [oligo $(\mathrm{TeC})$ diol] was prepared by the reaction of diethyl carbonate with 1,4-butanediol using lipase $\mathrm{CA}$. The typical preparation of the oligo $(\mathrm{TeC})$ diol using 1,4-butanediol and diethyl carbonate was carried out as follows. A mixture of 1,4-butanediol (10 mmol) and diethyl carbonate $(10 \mathrm{mmol})$ was stirred with lipase CA $(600$ $\mathrm{mg}$ ) in bulk under atmospheric pressure at $70^{\circ} \mathrm{C}$ for 24 $h$. The pressure of the reaction vessel was then reduced to about $25 \mathrm{mmHg}$ and further reacted at the same temperature of $70{ }^{\circ} \mathrm{C}$ for $5 \mathrm{~h}$. After the reaction, the reaction mixture was dissolved in chloroform and the insoluble enzyme was removed by filtration. The chloroform was then evaporated to obtain the oligomer. The molecular weight of the oligomer was measured by SEC. The end group analyses were carried out using ${ }^{1} \mathrm{H}$ NMR and MALDI-TOF MS. The obtained oligomer was used for the synthesis of poly(carbonate-urethane) without further purification.

${ }^{1} \mathrm{H} \mathrm{NMR}\left(\mathrm{CDCl}_{3}\right): \delta=1.77\left(\mathrm{~m}, 4 \mathrm{H}, \mathrm{CH}_{2}\right), 3.64-3.73(\mathrm{~m}$, $\left.2 \mathrm{H}, \mathrm{OCOOCH}_{2} \mathrm{CH}_{2} \mathrm{CH}_{2} \mathrm{CH}_{2} \mathrm{OH}\right), 4.16\left(\mathrm{~m}, 4 \mathrm{H}, \mathrm{OCH}_{2}\right)$. IR $(\mathrm{KBr}): 2965,1454\left(\mathrm{CH}_{2}\right)$ and $1732 \mathrm{~cm}^{-1}$ (carbonate $\mathrm{C}=\mathrm{O}$ ).

2.3 Polymerization of Oligocarbonate Diols with Diisocyanates

The polymerization of hexamethylene diisocyanate with the oligo(TeC) diol or oligo(HC) diol was carried out in bulk forming poly(carbonate-urethane). As a typical example, the oligo $(\mathrm{TeC})$ diol $(2.73 \mathrm{~g})$ was dried by stirring in a glass flask under vacuum for $3 \mathrm{~h}$ at $75^{\circ} \mathrm{C}$. To this was added the equivalent of 1,6-hexamethylene diisocyanate and the reaction mixture was evacuated for $1 \mathrm{~min}$, then the flask was sealed and reacted for $72 \mathrm{~h}$ at $80^{\circ} \mathrm{C}$. Consumption of the isocyanate was confirmed by FT-IR spectra. The molecular weight was determined by $\mathrm{SEC}$, and the $T_{\mathrm{g}}$ was measured by DSC.

${ }^{1} \mathrm{H}$ NMR $\left(\mathrm{CDCl}_{3}\right): \delta=1.33\left(\mathrm{OCONHCH}_{2} \mathrm{CH}_{2} \mathrm{CH}_{2}\right)$, $1.49\left(\mathrm{OCONHCH}_{2} \mathrm{CH}_{2} \mathrm{CH}_{2}\right), 1.77(\mathrm{~m}, 4 \mathrm{H}, \quad \mathrm{OCOO}$ $\mathrm{CH}_{2} \mathrm{CH}_{2}$ ), 3.15 (m, $\left.4 \mathrm{H}, \mathrm{OCONHCH} \mathrm{CH}_{2} \mathrm{CH}_{2}\right), 4.07$ (m, $\left.4 \mathrm{H}, \mathrm{NHCOOCH}_{2} \mathrm{CH}_{2}\right), 4.16\left(\mathrm{~m}, 4 \mathrm{H}, \mathrm{OCOOCH}_{2}\right)$. IR(KBr): $3500-3200,1550,1250,760(\mathrm{NH}), 1750-1680$ $(\mathrm{C}=\mathrm{O}), 3000-2800,1450,1400,800 \mathrm{~cm}^{-1}\left(\mathrm{CH}_{2}\right)$.

2.4 Preparation of Poly(carbonate-urethane) Film

The polymer was dissolved in chloroform to produce a viscous solution. A small amount of the insoluble polymeric fraction was filtered off through a bolting cloth made from nylon 66 (mesh $255,57 \mu \mathrm{m}$ open pitch). The filtrate was then poured into a Teflon Petri dish. The solvent was gradually removed under a draft to form the poly(carbonate-urethane) film.

\subsection{Enzymatic Degradation}

Enzymatic degradation of the poly(carbonate urethane) was conducted by using lipase CA in anisol. The degradation products were analyzed by SEC and MALDI-TOF MS.

\section{RESULTS AND DISCUSSION}

3.1 Enzymatic Oligomerization of Diethyl Carbonate and 1,4-Butanediol

It was found that 1,4-butanediol was reacted with an equivalent of diethyl carbonate in the presence of lipase CA to produce oligo(TeC) diol with an $M_{\mathrm{n}}$ of 1,500 and $M_{\mathrm{W}} / M_{\mathrm{n}}$ of 1.7 in $84 \%$ yield. The produced oligomer had almost all hydroxy groups at both ends as analyzed by MALDI-TOF MS as shown in Fig.1. It was confirmed that a molecular mass $(m / z)$ of $\left(116 \mathrm{n}+\mathrm{Na}^{+}\right)$, which was equivalent to the structure of the tetramethylene carbonate oligomer, was obtained. The ethyl carbonate terminated linear oligomer (Scheme 2 (a)), which had a molecular mass $(\mathrm{m} / \mathrm{z})$ of 44 smaller than that of the corresponding diol type oligomer, was scarcely detected. This was also confirmed by ${ }^{1} \mathrm{H}$ NMR. That is, no peak corresponding to the ethyl carbonate terminal at $\delta=1.32$ ( $\mathrm{t}, J=7.3 \mathrm{~Hz}, \mathrm{OCOOCH}_{2} \mathrm{CH}_{3}$ ) was detected.[14] Also, the cyclic oligomer (Scheme 2 (b)), which had a molecular mass of 90 smaller than that of the corresponding diol type oligomer, was scarcely detected. The equivalent amount of diethyl carbonate was suitable 
for the production of the dihydroxy terminated tetramethylene carbonate oligomers due to the slight degradation of diethyl carbonate as a side reaction by the lipase. However, the equimolar reaction of 1,4-butanediol and diethyl carbonate produced a low-molecular weight oligomer. On the other hand, the oligomerization of two equivalents of diethyl carbonate with 1,4-butanediol produced the oligomer with higher $M_{\mathrm{n}}$ of 4,800 , but with a $70 \%$ ethyl carbonate terminal and a $30 \%$ hydroxy terminal. In a similar way, oligo(HC) diol with an $M_{\mathrm{n}}$ of 3,400 were prepared by the reaction of an equivalent of diethyl carbonate with 1,6-hexanediol using lipase CA in $91 \%$ yield.

$$
\mathrm{HO}\left(\mathrm{CH}_{2}\right)_{4} \circ\left[\mathrm{O}-\mathrm{O}-\mathrm{O}\left(\mathrm{CH}_{2}\right)_{4} \circ\right]_{n}
$$

oligo(tetramethylene carbonate) diol

[oligo(TeC) diol]: $\mathrm{M}=116 \mathrm{n}+90$

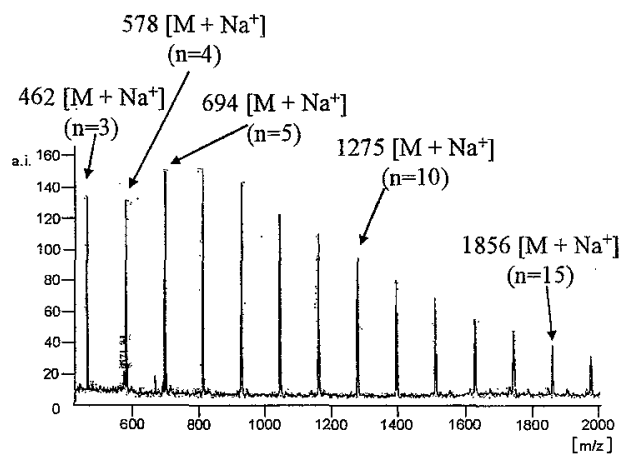

Fig.1. Typical MALDI-TOF mass spectrum of oligo(TeC) diol obtained by oligomerization of diethyl carbonate $(10 \mathrm{mmol}), 1,4$-butanediol $(10 \mathrm{mmol})$, and lipase $\mathrm{CA}(600 \mathrm{mg})$ at $70^{\circ} \mathrm{C}$ for $24 \mathrm{~h}$ under atmospheric pressure and $5 \mathrm{~h}$ under $25 \mathrm{mmHg}$.

(a)

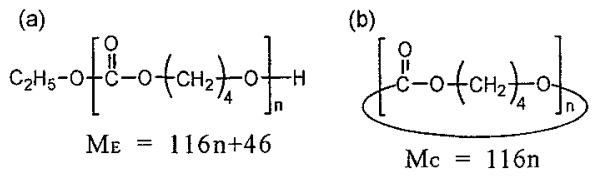

Scheme 2

3.2 Polymerization of Hexamethylene Diisocyanate with Oligo(TeC) Diol or Oligo(HC) Diol

Hexamethylene diisocyanate was used for the production of polyurethane because hexamethylene diisocyanate was one of the commonly used diisocyanates, and the aliphatic polyurethane might be feasible for biodegradation compared to the aromatic polyurethane. The poly(carbonate-urethane) was prepared by the polymerization of the equivalent amounts of the oligocarbonate diol and hexamethylene diisocyanate in bulk without a catalyst at $80^{\circ} \mathrm{C}$ for $72 \mathrm{~h}$. Commercially available oligo(HC) diols were also used in addition to the enzymatically prepared oligo(TeC) diol for the production of poly(carbonate urethane). Poly(tetramethylene carbonate-urethane) (PTeCU) with an $M_{\mathrm{n}}$ of 36,400 was produced by the polymerization of the hexamethylene diisocyanate and oligo $(\mathrm{TeC})$ diol in bulk. Also, poly(hexamethylene carbonate-urethane)s (PHCU) with $M_{\mathrm{n}} \mathrm{s}$ of 36,900 and 26,700 were produced by the polymerization of the hexamethylene diisocyanate and commercially available oligo(HC) diols. Typical polymerization results of the poly(carbonate-urethane)s are shown in Table I.

Table I. Poly(carbonate-urethane)s by polymerization of hexamethylene diisocyanate and oligocarbonate diols.

\begin{tabular}{|c|c|c|c|c|c|c|c|c|}
\hline \multirow[b]{2}{*}{ Entry } & \multicolumn{2}{|c|}{ Oligocarbonate diol } & & \multicolumn{5}{|c|}{ Poly(carbonate-urethane) } \\
\hline & & $M_{n}$ & & $M_{\mathfrak{n}}$ & $M_{\mathrm{W}} / M_{\mathrm{n}}$ & $\begin{array}{c}\text { Tensile } \\
\text { strength } \\
(\mathrm{MPa})\end{array}$ & $\begin{array}{c}\text { Elongation } \\
(\%)\end{array}$ & $\begin{array}{l}T_{g} \\
\left.{ }^{\circ} \mathrm{C}\right)\end{array}$ \\
\hline 1 & oligo( $\mathrm{TeC})$ diol & 1,500 & $\mathrm{PTeCU}$ & 36,400 & 2.8 & 18.7 & 410 & .29 \\
\hline 2 & oligo(HC)diol & 1,500 & $\mathrm{PHCU}$ & 36,900 & 1.4 & 1.98 & 33 & 42 \\
\hline 3 & oligo(HC)tiol & 3,900 & PHCU & 26,700 & 1.5 & 1,82 & 10 & .50 \\
\hline
\end{tabular}

3.3 Enzymatic Degradation of Poly(carbonate-urethane)

The poly(carbonate-urethane) was designed so as to subject the main-chain cleavage by the hydrolysis enzyme. The enzymatic degradations of PTeCU and PHCU were carried out by $200 \%$ lipase CA using 4 $\mathrm{mg} / \mathrm{mL} \mathrm{PTeCU}$ in anisole at $110^{\circ} \mathrm{C}$ for $24 \mathrm{~h}$. In order to avoid the decarboxylation loss, anhydrous anisole was used as the solvent. The SEC profile changes before and after the degradation of PTeCU are shown in Fig.2. It was found that the parent polymer peak shifted to the oligomer region. However PHCUs were not degraded into the oligomers by lipase CA under the same conditions.

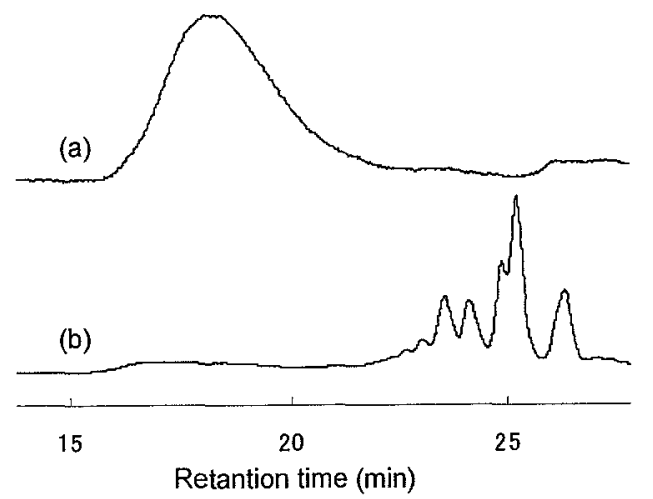

Fig.2. SEC profiles of the degradation products of 4 $\mathrm{mg} / \mathrm{mL}$ PTeCU in anisol by $200 \%$ of lipase CA at $110{ }^{\circ} \mathrm{C}$ for $24 \mathrm{~h}$. (a) before degradation. (b) after degradation.

The molecular structure of the enzymatic degradation products was analyzed by MALDI-TOF MS and the results are shown in Fig.3. The MALDI-TOF MS and ${ }^{1} \mathrm{H}$ NMR analyses indicated that the degradation products mainly consisted of cyclic structures. For example, the peaks at $397,513,655$ and $771 \mathrm{~m} / 2$ were identified as cyclic oligomers. The peaks at $371,487,629$ and 745 $\mathrm{m} / \mathrm{z}$ corresponded to both cyclic and linear forms from the calculated values. However, from the ${ }^{1} \mathrm{H}$ NMR, methylene protons adjacent to the terminal hydroxy group were scarcely detected. This indicated the absence of any linear structure in the degradation products. These results might be reasonable because no water was added during the enzymatic degradation in anisol. In addition, it was reported that the enzymatic degradation of polycarbonates, polyesters, poly(carbonate-urethane) 
and poly(ester-urethane) by lipase in organic solvent exclusively produced the corresponding cyclic oligomers.[12, 13, 15-18] Also, these enzymatic degradations might be applicable to the chemical recycling of PTeCU. Details of the depolymerization of PTeCU and the repolymerization as a chemical recycling will be analyzed in the subsequent paper.

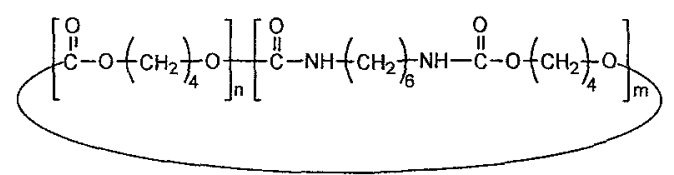

cyclic structure: $M=116 n+284 m$

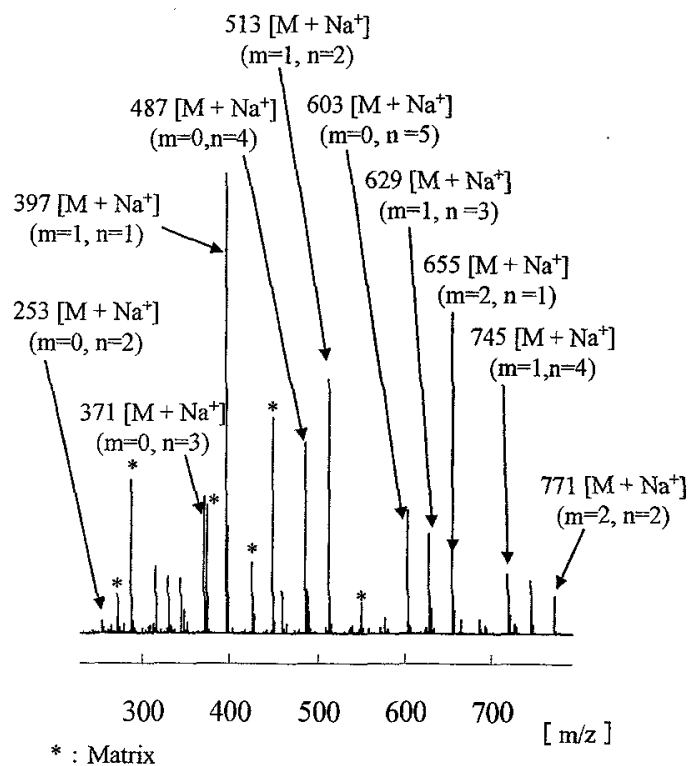

Fig.3. MALDI-TOF mass spectrum of the degradation products of $4 \mathrm{mg} / \mathrm{mL} \mathrm{PTeCU}$ in anisol by $200 \%$ lipase $\mathrm{CA}$ at $110^{\circ} \mathrm{C}$ for $24 \mathrm{~h}$.

3.4 Thermal and Mechanical Properties of Poly(carbonate-urethane)

The thermal properties of poly(carbonate-urethane) were measured using DSC and the results are shown in Table 1. When compared with the $T_{\mathrm{g}}$ for the soft segment of poly(carbonate-urethane), a lower $T_{\mathrm{g}}$ was observed for PHCU having oligo(HC) diol as the soft segment when compared to PTeCU conatining oligo $(\mathrm{TeC})$ diol. On the other hand, no significant difference was observed for the $T_{\mathrm{m}}$ values between PTeCU and PHCU. No clear $T_{\mathrm{c}}$ was observed for both PTeCU and PHCU.

The poly(carbonate-urethane) film was prepared and cut into dumbbell-shaped specimens and their mechanical properties were measured. These results are shown in Table 1 . The tensile strength and elongation of the PTeCU sample (100 $\mu \mathrm{m}$ thick) were $18.7 \mathrm{MPa}$ and $410 \%$, respectively. These values were slightly superior to those of the polyethylene film (LDPE). That is, the tensile strength and elongation of the LDPE film $(30 \mu \mathrm{m}$ thick) were $10 \mathrm{MPa}$ and $440 \%$, respectively.[19] On the other hand, the PTeCU film was 10 times stronger than the PHCU film. The tetramethylene carbonate unit increased both the tensile strength and elongation of the film when compared with the hexamethylene carbonate unit as a soft segment of the polyurethane.

\section{CONCLUSION \\ Environmentally benign poly(alkylene} carbonate-urethane) was prepared by the polymerization of hexamethylene diisocyanate with oligo( $\mathrm{TeC}$ ) diol as the soft segment. The oligo(TeC) diol with an $M_{\mathrm{n}}$ of 1,500 was prepared by the reaction of 1,4-butanediol and the equivalent amount of diethyl carbonate by lipase CA in $84 \%$ yield. The tensile strength and elongation of the PTeCU film with an $M_{\mathrm{n}}$ of 36,400 were $18.7 \mathrm{MPa}$ and $410 \%$, respectively. The PTeCU was enzymatically degraded in anisol into the cyclic oligomers which can be used for repolymerization.

Acknowledgements: Immobilized lipase from Candida antarctica (Novozym 435) was kindly supplied by Novozymes Japan Ltd. (Chiba, Japan).

[1] Y. W. Tang, R. S. Labow, J. P. Santerre, J. Biomed. Mater. Res., 56, 516-528 (2001).

[2] Y. W. Tang, R. S. Labow, J. P. Santerre, Biomaterials, 24, 2805-2819 (2003).

[3] G. T. Howard, Int. Biodet. Biodegr., 49, 245-252 (2002).

[4] S. Owen, T. Otani, S. Masaoka, T. Ohe, Biosci. Biotechnol. Biochem., 60, 244-248 (1996).

[5] T. Ohshiro, M. Shinji, Y. Morita, Y. Takayama, Y. Izumi, Appl. Microbiol. Biotechnol., 48, 546-548 (1997). [6] R. T. Darby, A. M. Kaplan, Appl. Microbiol, 16, 900-905 (1968).

[7] Y. Tokiwa, T. Suzuki, K. Takeda, Agric. Biol. Chem. 52, 1937-1943 (1988).

[8] J. P. Santerre, R. S. Labow, D. G. Duguay, D. Erfle, G. A. Adams, J. Biomed. Mater. Res., 28, 1187-1199 (1994).

[9] G. B. Wang, J. P. Santerre, R. S. Labow, J. Chromatog., B 698, 69-80 (1997).

[10] T. Nakajima-Kambe, Y. Shigeno-Akutsu, N. Nomura, F. Onuma, T. Nakahara, Appl. Microbiol. Biotechnol., 51, 134-140 (1999).

[11] I. Dupret, C. David, M. Colpaert, J.-M. Loutz, C. Wauven, Macromol. Chem. Phys., 200, 2508-2518 (1999).

[12] Y. Soeda, K. Toshima, S. Matsumura, Macromol. Biosci., 4, 721-728 (2004).

[13] Y. Soeda, K. Toshima, S. Matsumura, Macromol. Biosci., 5, 277-288 (2005).

[14] S. Matsumura, S. Harai, K. Toshima, Macromol. Chem. Phys., 201, 1632-1639 (2000).

[15] S. Matsumura, Macromol. Biosci., 2, 105-126 (2002).

[16] S. Okajima, R. Kondo, K. Toshima, S. Matsumura, Biomacromolecules, 4, 1514-1519 (2003).

[17] Y. Takahashi, S. Okajima, K. Toshima, S. Matsumura, Macromol. Biosci., 4, 346-353 (2004).

[18] Y. Osanai, K. Toshima, S. Matsumura, Green Chem., 5, 567-570 (2003).

[19] O. Koyashiki, Japan Plastics, 10, 37-39 (2001) (in Japanese).

(Received December 10, 2006; Accepted February 19, 2007) 